ScIDice

\section{Anti - Oxidant and Anti - Inflammatory Properties Of Annonamuricata Mediated Zinc Oxide Nanoparticles - An In vitro Study}

\section{International Journal of Dentistry and Oral Science (IJDOS) ISSN: 2377-8075}

Arthi. $\mathrm{S}^{1^{*}}$, Pratibha Ramani², Rajeshkumar $\mathrm{S}^{3}$

${ }^{1}$ MDS Student, Department of Oral and Maxillofacial Pathology, Saveetha Institute of Medical and Technical Science, Saveetha University, Chennai 600077, India.

${ }^{2}$ Professor and Head, Department of Oral and Maxillofacial Pathology, Saveetha Dental College and Hospitals, Saveetha Institute of Medical and Technical Science, Saveetha University, Chennai 600077, India.

${ }^{3}$ Associate Professor, Nanobiomedicine Lab, Department of Pharmacology, Saveetha Dental College and Hospitals, Saveetha Institute of Medical and Technical Science, Saveetha University, Chennai 600077, India.

\title{
Abstract
}

Background: Medicinal plants are widely regarded as the foundation for health protection and treatment. Annonamuricata . (A. muricata) is an Annonaceae plant and a variety of medicinal applications have been recorded worldwide, ranging from the use of leaves, bark, stems, fruits, and seeds of A.muricata. In A. Muricata, there are more than 212 bioactive compounds and the primary constituents are acetogenins, alkaloids, and phenols.

Aim: To study the anti-inflammatory and antioxidant activity of zinc oxide nanoparticles synthesisedAnnonamuricata leaves extract.

Materials and Methods: After the ethanol extract leaves preparation and zinc oxide nanoparticle characterisation, antioxidant activity through DPPH assay and antiinflammatory activity

through albumin denaturation assay was done at different levels of concentration.

Results: At higher concentrations ,A.muricata exhibited anti inflammatory and antioxidant activities in comparison to conventional agents.

Keywords: Annonamuricata; Graviola; Soursop; Acetogenins; Anti Inflammatory; Antioxidant; Zinc Oxide Nanoparticles.

\section{Introduction}

Annonamuricata. (A. muricata) is an Annonaceae plant that has received a lot of attention in recent years due to its therapeutic ability.[1, 2] The Annonaceae family has been known for a long time, and this species has gotten a lot of attention because of its bioactivity and common uses. Medicinal plants are widely regarded as the foundation for health protection and treatment.[3] A variety of medicinal applications have been recorded worldwide, ranging from the use of leaves, bark, stems, fruits, and seeds of A.muricata.The most popular preparation in traditional medicine is bark, root, seed, or leaf decoction, although there are several applications. In A. Muricata, there were more than 212 bioactive compounds. The primary constituents are acetogenins, alkaloids, and phenols $[1,2,4]$.
Natural antioxidants obtained from plant species have sparked concern due to their ability to guard against oxygen-derived free radicals, which are implicated in the production of a variety of diseases, like cancer, cardiovascular disease, arthritis, and degenerative diseases including Parkinson's and Alzheimer's. [5] A.muricata has been subjected to a slew of antioxidant tests.. The extract's composition varies depending on the solvent used. The antioxidant activity of methanolic, ethanolic, n-butanolic, and aqueous leaf extracts, for example, was calculated by DPPH. Aqueous extracts of fresh A. muricataleaves, for example, is 1000 times less potent than the commercial antioxidant butylatedhydroxytoluene.The anti-oxidant activity of the pulp as tested by ABTS, FRAP, and ORAC suggested that the antioxidant compounds from A. muricataare mostly lipophilic, with hydrogen donation as the mechanism of action [6]. Some of the methods used for determining the total antioxidant capacity included the free

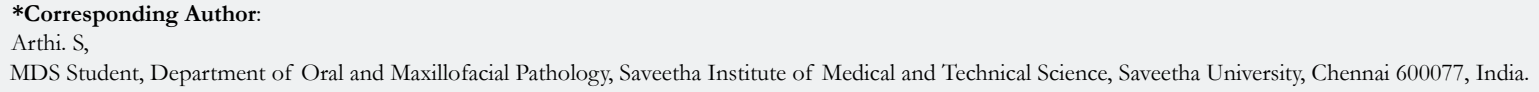

Copyright: Arthi. S 2021 . This is an open-access article distributed under the terms of the Creative Commons Attribution License, which permits unrestricted use, distribution and reproduction in any medium, provided the original author and source are credited. 
radical scavenging capacities using DPPH and the ABTS+ assays, determination of oxygen radicals by the ORAC assay, reduction power by the FRAP assay and b- carotene bleaching [1].

Inflammation is a rapidly growing area of research with potential intervention targets in a variety of disorders, including asthma, hypertension, Crohn's disease, Alzheimer's disease, cardiovascular disease, diabetes, elevated blood pressure, and, most notably, cancer.Due to the major adverse effects of steroid and Nonsteroidal Anti-inflammatory Drugs (NSAIDs), natural compounds used in nutritional supplements and herbal therapies, which have been used for years to reduce pain and inflammation, are gaining in popularity.A large number of natural compounds act by inhibiting inflammatory signalling channels, which are also targets of NSAIDs.[7]

Antinociception (pain sensitivity reduction) is thought to work by inhibiting cyclooxygenases (COX) and lipoxygenases (LOX) through inflammatory mediators like flavonoids found in plant extracts.

Annonamuricatahas been proven as an efficient antiinflammatory agent in various studies. [8] Number of in vitro studies have demonstrated the biomedical application of the plant. Furthermore, in xylene-induced ear edoema mice and Complete Freund's adjuvant (CFA)-induced arthritis rat models, leaves extract of Graviola was found to have a significant anti-inflammatory effect. In CFA-induced arthritis rats, they also found that proinflammatory cytokines such as tumour necrosis factor (TNF-) and interleukin-1 (IL-1) were significantly suppressed.The anti-inflammatory effects of A.muricata are thus shown to be mediated by inflammatory mediator suppression. [9]

Nanoparticles have specific physicochemical, optical, and biological properties that allow for the integration of multifunctional ca- pabilities that allow for the attachment of several therapies, resulting in more effective care. [10] The desired size, surface charge, gene and drug loading capability, and regulated release can all be easily engineered.Their optical properties have been used in MRI and ultrasound imaging as diagnostic agents. These vectors are nonviral vectors, and they can be considered superior to viral vectors in terms of carrying larger nucleic acid molecules and combination therapies with reduced immunogenic responses.

Zinc oxide $(\mathrm{ZnO})$ is a catalytic, semiconducting, piezoelectric, optoelectronic, and pyroelectric inorganic compound [11]. nanoparticle chemistry, nanoparticle synthesis has proved to be reducing or totally removing the use of high temperatures, pressures, hazardous substances, space, and resources used to set up equipment and heavy machinery for physical and chemical synthesis. Plant compounds coat the nanoparticles during the synthesis process, allowing for a wide range of biomedical applications based on the plant compound. [12]

\section{Materials And Method}

\section{Graviola Leaves Extract Preparation}

The leaves of Graviola were shade dried, powdered, and aqueous extract was prepared by Soxhlet apparatus for $8 \mathrm{~h}$ using rota evaporator (PBV-7D).1 gm of plant leaves extract was dissolved in $100 \mathrm{ml}$ of distilled water and boiled for 10-20 minutes and filtered by whatman filter paper.

\section{Zinc Nanoparticles Characterisation}

For zinc oxide nanoparticles. $40 \mathrm{ml}$ of plant extract was mixed with $50 \mathrm{ml}$ of $20 \mathrm{Mm}$ of Zinc sulphate and colour change was observed on 6 hourly basis. After nanoparticle formation, solution

Figure 1. Dried powdered leaves of $A$. muricata.

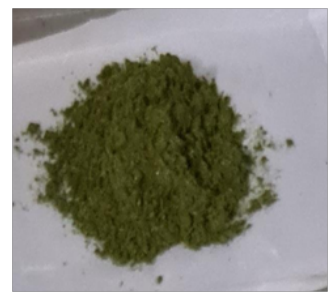

Figure 2. Ethanolic leaves extract of A.muricata.

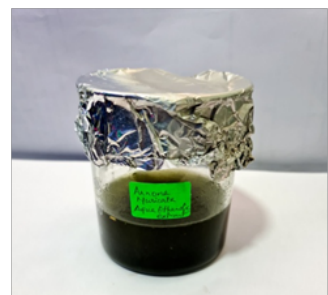

Figure 3. A. muricata mediated Zinc oxide nanoparticles after characterisation.

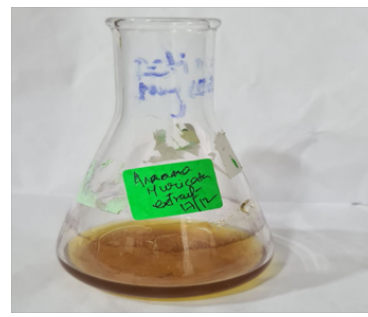


Figure 4. Anti inflammatory activity.

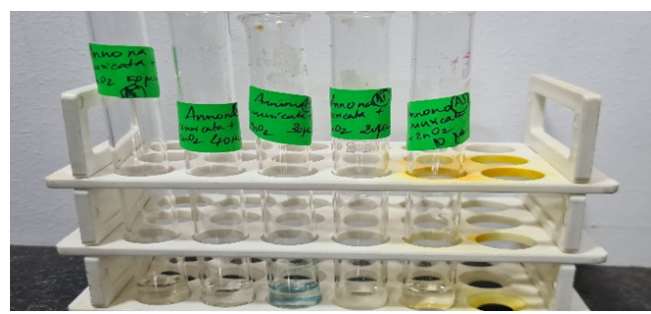

Figure 5. Antioxidant activity.

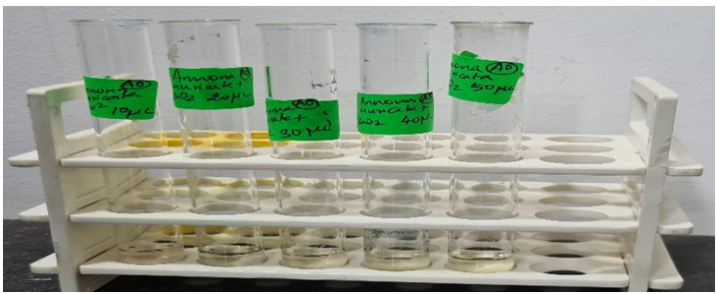

Figure 6. Represents anti inflammatory activity of A.muricata in comparison with diclofenac.

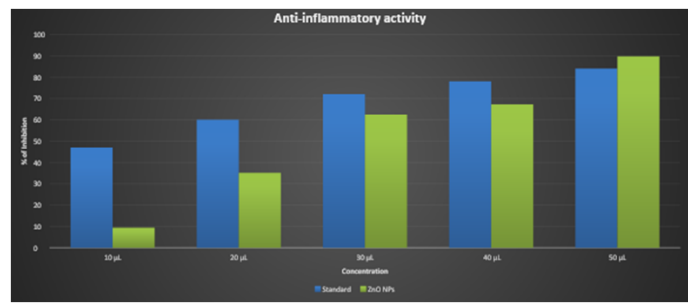

Figure 7. Represents antioxidant activity of A.muricata in comparison with Vitamin $c$.

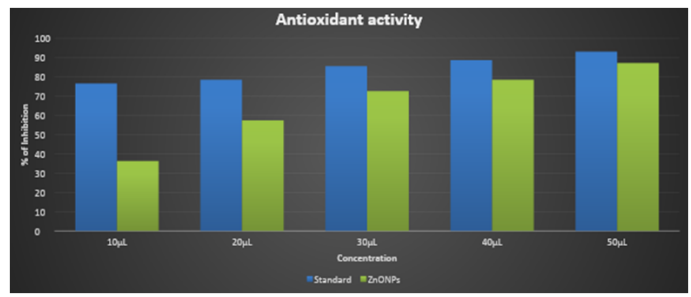

was centrifuged at $10000 \mathrm{rpm}$ for $15 \mathrm{mins}$. Pellet was collected and kept in a hot air oven and stored.

\section{Antioxidant Activity}

DPPH Method: DPPH assay was used to test the antioxidant activity of biogenic synthesized zinc oxide nanoparticles. Diverse concentrations $(2-10 \mu \mathrm{g} / \mathrm{ml})$ of Annonamuricata leaf extract interceded zinc oxide nanoparticle was mixed with $1 \mathrm{ml}$ of $0.1 \mathrm{mM}$ DPPH in methanol and $450 \mu \mathrm{l}$ of $50 \mathrm{mMT}$ TrisHCl buffer ( $\mathrm{pH} 7.4)$ and incubated for 30 minutes.Later, the reduction in the quantity of DPPH free radicals was assessed dependent on the absorbance at $517 \mathrm{~nm}$. BHT was employed as control. The percentage of inhibition was determined from the following equation,

$\%$ inhibition $=$ Absorbance of control- Absorbance of test sample $\times 100 /$ Absorbance of control

\section{Anti Inflammatory Activity}

Albumin Denaturation Assay: The anti-inflammatory activity of Annonamuricata leaf extract interceded zinc oxide nanoparticle was tested by $0.05 \mathrm{~mL}$ of Annonamuricata of various fixation $(10 \mu \mathrm{L}, 20 \mu \mathrm{L}, 30 \mu \mathrm{L}, 40 \mu \mathrm{L}, 50 \mu \mathrm{L})$ was added to $0.45 \mathrm{~mL}$ bovine serum albumin( $1 \%$ aqueous solution) and the $\mathrm{pH}$ of the mixture was acclimated to 6.3 utilizing a modest quantity of $1 \mathrm{~N}$ hydro- chloric acid. These samples were incubated at room temperature for $20 \mathrm{~min}$ and then heated at $55^{\circ} \mathrm{C}$ in a water bath for $30 \mathrm{~min}$. The samples were cooled and the absorbance was estimated spectrophotometrically at $660 \mathrm{~nm}$. Diclofenac Sodium was used as the standard. DMSO is utilized as a control. Percentage of protein denaturation was determined utilizing following equation,

$\%$ inhibition $=$ Absorbance of control- Absorbance of sample $\mathrm{x}$ 100/Absorbance control

\section{Results}

The anti-inflammatory activity of zinc oxide nanoparticles synthesised using Annonamuricata leaves extract is highest at $50 \mu \mathrm{L}$ concentration, where the absorbance is 0.934 at $660 \mathrm{~nm}$, which is as effective as the standard drug diclofenac, as shown by the findings. The findings also show that zinc oxide nanoparticles synthesised with Annonamuricata leaves extract have the highest antioxidant activity at $50 \mu \mathrm{L}$ with an absorbance of 1.136 , making them as effective as the regular drug vitamin $\mathrm{C}$.

\section{Discussion}

A good diet rich in natural fruits and vegetables has been linked to better health and a lower risk of diseases like cancer. Phytochemicals including phenols, phenolic acids, alkaloids, flavonoids, 
Table 1. Anti inflammatory activity of A.muricata.

\begin{tabular}{|c|c|c|}
\hline CONCENTRATIONS & WAVELENGTH & ABSORBANCE \\
\hline $50 \mu \mathrm{L}$ & $660 \mathrm{~nm}$ & 0.934 \\
\hline $40 \mu \mathrm{L}$ & $660 \mathrm{~nm}$ & 0.648 \\
\hline $10 \mu \mathrm{L}$ & $660 \mathrm{~nm}$ & 0.375 \\
\hline $20 \mu \mathrm{L}$ & $660 \mathrm{~nm}$ & 0.327 \\
\hline $30 \mu \mathrm{L}$ & $660 \mathrm{~nm}$ & 0.102 \\
\hline
\end{tabular}

Table 2. Antioxidant activity of A.muricata.

\begin{tabular}{|c|c|c|}
\hline CONCENTRATIONS & WAVELENGTH & ABSORBANCE \\
\hline $50 \mu \mathrm{L}$ & $517 \mathrm{~nm}$ & 1.136 \\
\hline $40 \mu \mathrm{L}$ & $517 \mathrm{~nm}$ & 0.926 \\
\hline $30 \mu \mathrm{L}$ & $517 \mathrm{~nm}$ & 0.774 \\
\hline $20 \mu \mathrm{L}$ & $517 \mathrm{~nm}$ & 0.714 \\
\hline $10 \mu \mathrm{L}$ & $517 \mathrm{~nm}$ & 0.628 \\
\hline
\end{tabular}

carotenoids, and vitamins all play a part in improving immunity. Graviola is a Portuguese variant of the common name Soursop. Graviola is high in secondary class metabolites including saponins, alkaloids, terpenoids, flavonoids, coumarins, and tannins, making it a promising antioxidant and anticancer medication [13]. Graviola leaves, fruits, and barks are used by herbalists to treat stomach problems, fever, parasitic infections, and hypertension.

DPPH is a type of unstable free radical that accepts an electron or hydrogen radical to transform into a stable diamagnetic molecule that is commonly used to study the radical scavenging behaviour of leaf extracts. Quantitative research showed that both extracts scavenge free radicals in a dose-dependent manner, which could be due to their electron donating properties.

The formation of auto-antigens in some arthritic diseases may be caused by denaturation of tissue proteins. Denaturation of tissue proteins is therefore a proxy for inflammatory and arthritic diseases. As a result, agents that prevent protein denaturation may be a good candidate for anti-inflammatory drug production. With this idea in mind, the in vitro test was done as a preliminary screen to check presence of anti-inflammatory property before doing the in vivo test. In the present study, the protein denaturation bioassay was selected for in vitro assessment of anti-inflammatory property of ethanolic extract of A. muricata leaf parts with a wide range of dose concentrations. [14]

In our study good Anti Inflammatory properties were evident when compared to the standard. The highest effect was evident at $50 \mu \mathrm{l}$ and the least was found in $10 \mu \mathrm{l}$ using albumin denaturation assay and analysed in a wavelength of $660 \mathrm{~nm}$. The efficiency of the Anti Inflammatory property increases with increase in concentration. The varying concentrations showing varying absorbance at $517 \mathrm{~nm}$ wavelength, at $10 \mu \mathrm{l}, 20 \mu \mathrm{l}, 30 \mu \mathrm{l}, 40 \mu \mathrm{l}, 50 \mu \mathrm{l}$ the absorbance found were $0.102,0.327,0.375,0.648,0.934$ respectively as mentioned in table 1 .

Similarly our study showed significantly good antioxidant properties when compared to the standard. At $50 \mu$ l concencentration the highest reading was noted as 1.136 using DPPH assay and further analysing in wavelength of $517 \mathrm{~nm}$. It was notable that the efficiency decreased with decreasing concentrations. The least efficiency was found in $10 \mu \mathrm{l}$. The varying concentrations of $10 \mu \mathrm{l}$, $20 \mu \mathrm{l}, 30 \mu \mathrm{l}, 40 \mu \mathrm{l}, 50 \mu \mathrm{l}$ at a wavelength of $517 \mathrm{~nm}$ showed an absorbance of $0.628,0.714,0.774,0.926,1.136$ respectively as mentioned in table 1.2

Gavamukulya et al. found that when ethanolic and aqueous extracts of Graviola leaves were tested on EACC, MDA, and SKBR3 cell lines, the aqueous extract had higher free radical inhibition and antioxidant activity than the ethanolic extract. Throughout their range of conceiving, the ethanolic extracts had a high selectivity for cancer spleen cells while sparing normal spleen cells. [15]. This is in accordance with our study where the anti inflammatory and antioxidant properties of A.muricata are emphasised.

Studies by Syed Najmuddin et al [16] stated that the effect of Annonamuricata as an antioxidant against lipid per- oxidation in $4 \mathrm{~T} 1$ tumor samples. The investigations was based on the of the level of malondialdehyde (MDA), where it was found that A.muricata has a good profile to be a candidate for breast cancer treatment .Also the article demonstrated the anti inflammatory property of A.muricata in breast cancer cell lines where there was reduced inflammation.Previously, JA Badmus et al [17] proved that the synthesized AgNPs using the leaf extract of A. muricata showed strong in vitro antioxidant activity against the $\mathrm{HaCaT}$ cell line. The synthesized AgNPs effectively scavenged DPPH in a dosedependent manner with IC50 values of $51.80 \mu \mathrm{g} / \mathrm{ml}$ against standard Trolox with $5.25 \mu \mathrm{g} / \mathrm{ml} \mathrm{[18-32].} \mathrm{These} \mathrm{studies} \mathrm{are} \mathrm{also}$ in line with our research, which explained A.muricata's anti-inflammatory and antioxidant properties.

As a result, based on previous research and our findings, it is reasonable to assume that, at higher concentrations, the antioxidant activity was comparable to vitamin $\mathrm{C}$, and the anti-inflammatory activity of A. Muricata controlled zinc oxide nanoparticles was comparable to that of commercial anti-inflammatory diclofenac.

\section{Conclusion}

With this backdrop, it can be concluded thatA.muricata mediated zinc oxide nanoparticles could exhibit anti inflammatory and 
antioxidant properties at higher concentrations against commercial agents thereby supporting the therapeutic potential of this nanoparticle leaf extract. Further investigations can be done to emphasise its various medical applications.

\section{References}

[1]. Akhir NA, Chua LS, Majid FA, Sarmidi MR. Cytotoxicity of aqueous and ethanolic extracts of Ficusdeltoidea on human ovarian carcinoma cell line. Journal of Advances in Medicine and Medical Research. 2011 Sep 2:397409

[2]. Institute NC, National Cancer Institute. Annona muricata [Internet]. Definitions. 2020

[3]. Ross IA. Annona muricata L [Internet]. Medicinal Plants of the World, Volume 1.p. 133-42.

[4]. Banerjee A, Das D, Maji BK, Mukherjee S. Anticancer effects of Annonamuricata with its acetogenins as bioactive compound. Cytology \& Histology International Journal. 2018;2(1):1-6.

[5]. Ross IA. Annona muricata [Internet]. Medicinal Plants of the World. 2003. p. 133-42.

[6]. Velázquez-Aponte RA, Cassé C. ANTIPROLIFERATIVE PROPERTIES OF ETHANOLIC AND AQUEOUS GRAVIOLA LEAF EXTRACTS ON TONGUE SQUAMOUS CELL CARCINOMA CELL LINE-25. Journal of Medical Case Reports and Reviews. 2020 Aug 21;3(08).

[7]. Roslida AH, Zuraini A, Tay CE, Chan PF. Anti-inflammatory and antinociceptive effects of Annonamuricata L.(Annonaceae) leaves extract. PlantaMedica. 2008 Jul;74(09):PA269.

[8]. Sanusi SB, Bakar MFA. Soursop-Annona muricata [Internet]. Exotic Fruits. 2018. p. 391-5.

[9]. Tay CE. Anti-inflammatory and Antinociceptive Effects of AnnonaMuricata L Leaves. 2007. $128 \mathrm{p}$.

[10]. Biju MP, Pyroja S, Rajeshkumar NV, Paulose CS. Molecular and Cellular Biochemistry [Internet]. Vol. 216. 2001. p. 65-70.

[11]. Rajeshkumar S, Sandhiya D. Biomedical applications of zinc oxide nanoparticles synthesized using eco-friendly method. Nanoparticles and their Biomedical Applications. 2020:65-93.

[12]. Vindhya PS, Jeyasingh T, Kavitha VT. Dielectric properties of zinc oxide nanoparticles using annonamuricata leaf. InAIP Conference Proceedings 2019 Mar 22 (Vol. 2082, No. 1, p. 080005). AIP Publishing LLC.

[13]. Abdul Wahab SM, Jantan I, Haque MA, Arshad L. Exploring the Leaves of Annonamuricata L. as a Source of Potential Anti-inflammatory and Anticancer Agents. Front Pharmacol. 2018 Jun 20;9:661. PubmedPMID: 29973884

[14]. Oyekachukwu AR, Elijah JP, Eshu OV, Nwodo OF. Anti-inflammatory effects of the chloroform extract of Annonamuricata leaves on phospholipase $\mathrm{A} 2$ and prostaglandin synthase activities. Translational Biomedicine. 2017;8:137.

[15]. Abdel-Rahman T, Hussein AS, Beshir S, Hamed AR, Ali E, El-Tanany SS. Antimicrobial Activity of Terpenoids Extracted from Annonamuricata Seeds and its Endophytic Aspergillusniger Strain SH3 Either Singly or in Combination. Open Access Maced J Med Sci. 2019 Aug 30;7(19):3127-3131. PubmedPMID: 31949503.

[16]. Hamid RA, Foong CP, Ahmad Z, Hussain MK. Antinociceptive and antiulcerogenic activities of the ethanolic extract of Annonamuricata leaf. RevistaBrasileira de Farmacognosia. 2012 Jun;22(3):630-41.

[17]. Badmus JA, Oyemomi SA, Adedosu OT, Yekeen TA, Azeez MA, Adebayo EA, et al. Photo-assisted bio-fabrication of silver nanoparticles using An- nonamuricata leaf extract: exploring the antioxidant, anti-diabetic, antimicrobial, and cytotoxic activities. Heliyon. 2020 Nov 3;6(11):e05413. PubmedPMID: 33195844.

[18]. Pinheiro ET, Gomes BP, Ferraz CC, Sousa EL, Teixeira FB, Souza-Filho FJ. Microorganisms from canals of root-filled teeth with periapical lesions. IntEndod J. 2003 Jan;36(1):1-11. PubmedPMID: 12656508.

[19]. Bystrom A, Claesson R, Sundqvist G. The antibacterial effect of camphorated paramonochlorophenol, camphorated phenol and calcium hydroxide in the treatment of infected root canals. Endod Dent Traumatol. 1985 Oct;1(5):170-5. PubmedPMID: 3865763.

[20]. Gomes BP, Lilley JD, Drucker DB. Variations in the susceptibilities of components of the endodontic microflora to biomechanical procedures. IntEndod J. 1996 Jul;29(4):235-41. PubmedPMID: 9206439.

[21]. Molander A, Reit C, Dahlén G, Kvist T. Microbiological status of root-filled teeth with apical periodontitis. IntEndod J. 1998 Jan;31(1):1-7. PubmedPMID: 9823122

[22]. Govindappa M, Hemashekhar B, Arthikala MK, Rai VR, Ramachandra YL. Characterization, antibacterial, antioxidant, antidiabetic, anti-inflammatory and antityrosinase activity of green synthesized silver nanoparticles using $\mathrm{Ca}$ lophyllumtomentosum leaves extract. Results in Physics. 2018 Jun 1;9:400-

[23]. Nair B, Pradeep T. Coalescence of nanoclusters and formation of submicron crystallites assisted by Lactobacillus strains. Crystal growth \& design. 2002 Jul 3;2(4):293-8

[24]. Narayanan KB, Sakthivel N. Biological synthesis of metal nanoparticles by microbes. Adv Colloid Interface Sci. 2010 Apr 22;156(1-2):1-13. PubmedPMID: 20181326.

[25]. Chaloupka K, Malam Y, Seifalian AM. Nanosilver as a new generation of nanoproduct in biomedical applications. Trends Biotechnol. 2010 Nov;28(11):580-8. PubmedPMID: 20724010.

[26]. Das G, Patra JK, Debnath T, Ansari A, Shin HS. Investigation of antioxidant, antibacterial, antidiabetic, and cytotoxicity potential of silver nanoparticles synthesized using the outer peel extract of Ananascomosus (L.). PLoS One. 2019 Aug 12;14(8):e0220950. PubmedPMID: 31404086.

[27]. Coria-Téllez AV, Montalvo-Gónzalez E, Yahia EM, Obledo- Vázquez EN. Annonamuricata: a comprehensive review on its traditional medicinal uses, phytochemicals, pharmacological activities, mechanisms of action and toxicity. Arabian J Chem. 2016; 1:1-4.

[28]. Diva G, Rama M, Puttey JS, Sandhu SS. Screening of endophytic fungi isolated from some medicinal plants in Jabalpur region for antibacterial activity. World Journal of Pharmacy and Pharmaceutical Sciences (WJPPS). 2014;3(7):1655-66.

[29]. Cassé C. Molecular mechanisms of Annonamuricata anti-proliferative/ anti-cancer properties. Review Article Biomedical Genetics and Genomics. 2018;4(1):1-4.

[30]. Cunha LC, de Morais SA, de Aquino FJ, Chang R, de Oliveira A, Martins $\mathrm{MM}$, et al. Bioassay-guided fractionation and antimicrobial and cytotoxic activities of Cassia bakeriana extracts. RevistaBrasileira de Farmacognosia. 2017 Feb;27(1):91-8.

[31]. Magadi VP, Ravi V, Arpitha A, Litha, Kumaraswamy K, Manjunath K. Evaluation of cytotoxicity of aqueous extract of Graviola leaves on squamous cell carcinoma cell-25 cell lines by 3-(4,5-dimethylthiazol-2-Yl) -2,5-diphenyltetrazolium bromide assay and determination of percentage of cell inhibition at G2M phase of cell cycle by flow cytometry: An in vitro study. ContempClin Dent. 2015 Oct-Dec;6(4):529-33. PubmedPMID: 26681860.

[32]. Nguyen TT, Parat MO, Hodson MP, Pan J, Shaw PN, Hewavitharana AK. Chemical Characterization and in Vitro Cytotoxicity on Squamous Cell Carcinoma Cells of Carica papaya Leaf Extracts. Toxins (Basel). 2015 Dec 24;8(1):7. PubmedPMID: 26712788. 